\title{
JÓVENES UNIVERSITARIOS: PERCEPCIONES Y ENCUESTAS SOBRE CONFLICTO ARMADO Y PAZ EN COLOMBIA
}

\section{UNIVERSITY YOUTH: PERCEPTIONS AND SURVEYS REGARDING ARMED CONFLICT AND PEACE IN COLOMBIA}

\author{
Jaime Andrés Wilches Tinjacál \\ jawilches@unisalle.edu.co \\ Mauricio Hernández Pérez ${ }^{2}$ \\ mhernandezp@unisalle.edu.co
}

Fecha de recepción: 12 julio 2016 - Fecha de aceptación: 11 enero 2017

\begin{abstract}
Resumen
El artículo tiene como objetivo identificar los referentes conceptuales y las estrategias metodológicas que se han utilizado para dar cuenta de las reacciones de la sociedad civil, en torno al proceso de paz que se adelanta entre el gobierno de Juan Manuel Santos y las Fuerzas Armadas Revolucionarias de Colombia (FARC). Luego de realizado este rastreo se evidenció, que las encuestas asociadas a las percepciones son la estrategia privilegiada de centros de pensamiento, investigadores y medios de comunicación, para justificar sus perspectivas de análisis frente a una salida negociada del conflicto armado. De acuerdo a lo anterior, se formuló una propuesta metodológica encaminada a realizar una encuesta a quinientos jóvenes universitarios de instituciones de educación superior públicas y privadas. Los resultados evidenciaron que las preguntas asociadas a la bipolaridad guerra - paz son más fáciles de responder que las asociadas al reconocimiento de actores, discursos y estrategias que han incidido en la comprensión del enfrentamiento bélico en Colombia. Aún más complejo cuando se solicita proponer soluciones o ideas en un posible escenario de posconflicto. Por último, se proponen algunas consideraciones finales que invitan a construir estrategias pedagógicas que logren incidir en las personas jóvenes, como actores claves para movilizar prejuicios, desconocimientos e indiferencias en los retos que supone la construcción de paz.

Palabras clave: Proceso de Paz, Universidad, Representaciones Sociales, Posacuerdo, Pedagogía.
\end{abstract}

\begin{abstract}
The purpose of this paper is to find conceptual guidelines and methodological strategies used to identify civil society's reactions to the current peace process between the government of Juan Manuel Santos and the Colombian Revolutionary Armed Forces (FARC). It was found that perception surveys are the preferred strategy of think tanks, researchers and the media, to justify their perspectives regarding the analysis of a negotiated end of the conflict. According to this, a methodological proposal was formulated in order to apply a survey to five hundred university students from both private and public universities. The results showed that questions associated to a dichotomy war/peace are easier to answer than
\end{abstract}

1 Docente, Universidad de La Salle, Investigador Instituto de Paz (IPAZUD) Universidad Distrital Francisco José de Caldas 
the ones associated to the recognition of actors, discourses and strategies that have influenced the understanding of Colombia's armed struggle. Even more complex when a proposal or idea for a solution in a possible scenario of post-conflict is requested. Lastly, some considerations are made that invite to build pedagogical strategies to influence young people (as key actors) to abandon the prejudices, lack of knowledge and indifference associated with the challenges that the construction of peace involves.

Key Words: Peace Process, University, Social representations, Post-conflict, Pedagogy.

\section{Introducción}

Uno de los problemas para preguntarse por qué en Colombia los sectores sociales se sienten ajenos al conflicto armado y no parecen tener mayor voluntad política para transformar esta actitud; está relacionado con un abordaje limitado como por ejemplo: trabajar las encuestas con definiciones imprecisas y ambiguas sobre conceptos claves como percepciones, opiniones y creencias, las cuales terminan instaurándose como verdades absolutas o fotografías fieles de realidades, que, por supuesto, son mucho más complejas.

En este sentido, las encuestas tienen más resonancia que ejercicios investigativos, pues las primeras le dan audiencia a los medios de comunicación, diseñan titulares atractivos y opiniones reactivas y eufóricas en una sociedad seducida por las redes sociales y la proliferación de espacios informativos. Se hace necesario entonces interrogarse sobre un asunto fundamental: ¿es la sociedad tan indiferente o prejuiciosa a las teorías y tramas del enfrentamiento bélico en Colombia o el asunto radica en que las preguntas y los abordajes llevan a reafirmar dichas creencias? Es más fácil preguntarle a la sociedad: ¿usted está de acuerdo que las FARC asesinen a civiles? (respuesta que la más elemental de las personas encuestadas responderían con un: "No" rotundo) o realizar un ejercicio de largo aliento en el que se escoja un sector de la sociedad para indagar cómo entienden el conflicto y cuáles propuestas tendrían para que el asesinato a personas inocentes se detenga en procura de un respeto a los derechos humanos.

Estas preguntas son abordadas en este artículo con una estructura que se divide en cuatro secciones: la primera parte, realiza un abordaje conceptual sobre la diferencia entre percepciones y otras categorías conceptuales que señalan la importancia de explorar con más cuidado la forma cómo la realidad se construye en la vida cotidiana. En la segunda sección, se presentan las encuestas que en los últimos años han tenido mayor impacto en Colombia, de acuerdo al poder, estatus y credibilidad de sus autores. En la tercera parte se exponen los resultados y tendencias del ejercicio estadístico que se menciona en líneas anteriores; y la cuarta y última parte, realiza una reflexión sobre los retos que se tienen en el momento de articular las encuestas más allá del efectismo que puede generar en la opinión pública, pero también cómo los ejercicios investigativos están en el reto de hacerse más comprensibles y articularse a este tipo de estrategias, si es que se quiere una sociedad movilizada en la solución progresiva del conflicto armado en Colombia.

\section{Esbozo sobre el conceptode percepción}

El interés de este apartado se enfoca en presentar un breve acercamiento conceptual a la idea de percepción, sin con esto pretender agotar en detalle la misma y de esta manera identificar la importancia de las percepciones en la comprensión y análisis de los hechos sociales. En este estudio, se procurará entrever cómo dentro de los mecanismos empleados para el estudio de la percepción se asume este concepto como algo sobreentendido, tanto por quienes diseñan los instrumentos (personas expertas) o mecanismos para la recolección y análisis de las informaciones, como por parte de aquellos de quienes se obtiene la misma (la ciudadanía). El acercamiento mostrará que tras de esto, no solamente se encuentran dificultades de orden conceptual y epistémico, sino además un entramado de orden psicológico que tendría que ser analizado cuando al momento de referirse a estudios de percepción social se refiere. 
Aun cuando la teorización y complejidad que trae consigo las aproximaciones disímiles y complementarias que sobre la percepción se hace en diferentes campos del saber humano, lo cierto es que la idea común que atraviesa a las mismos es que esta noción tiene que ver con cómo se logra una apropiación de la realidad o, en otros términos, la comprensión de lo social; es decir, de lo que es construido a partir de las experiencias de los diferentes sujetos. Sin embargo, es frente a este planteamiento donde se encuentra una de las principales dificultades en el intento exploratorio de la definición misma. Si bien, la percepción es un fenómeno individual y subjetivo, ¿cómo trasladar esto al plano de lo colectivo y de lo social? ¿Es posible hablar de percepción social cuando ésta es algo individual?

Por otra parte, en el intento definitorio de percepción, existen conceptos que tienden a asociarse a éste, a punto de traslaparse en algunas oportunidades. Estos conceptos han sido identificados por algunos autores como sistemas ideacionales de lo social, "entendidos como concepciones distintas del conocimiento del mundo social" (Serna, Oviedo \& Bravo, 2010, p.141). Es decir, corresponden a producciones individuales y colectivas, con origen en lo social, y mediante las que se pretende una comprensión de la realidad.

Aunque sería imposible agotar en detalle las distinciones entre cada uno de estos "sistemas ideacionales de lo social", se podría señalar, a manera de inventario, que dentro de estos se manifiestan las representaciones sociales (Araya, 2002), las cuales corresponden a una forma de conocimiento en la que sujetos sociales, aprehenden acontecimientos de la vida diaria. Constituyen una manera de interpretar y pensar la realidad; es una forma de conocimiento social que pertenece a un determinado grupo o sociedad y que se hace posible en tanto existe un elemento comunicativo que permite su comprensión al interior de la misma. Quizás el trabajo más destacado sobre el análisis de esta noción, - que posteriormente se convertiría en teoría- corresponde a la tesis doctoral de Moscovici publicada en 1961: "La psychanalyse, son imàge et son public" en donde la representación social es entendida, precisamente, como una:

modalidad particular del conocimiento, cuya función es la elaboración de los comportamientos y la comunicación entre los individuos[...] La representación es un corpus organizado de conocimientos y una de las actividades psíquicas gracias a las cuales los hombres hacen inteligible la realidad física y social, se integran en un grupo o en una relación cotidiana de intercambios, liberan los poderes de su imaginación. (Moscovici, 1979, pp.17-18)

Por otra parte, encontramos los imaginarios sociales, entendidos como "esquemas socialmente construidos, que nos permiten percibir, explicar e intervenir en lo que cada sistema social diferenciado, se tenga por realidad" (Pintos, 2006, p.31) aunque vale la pena señalar, y de una forma más simple, que cuando se habla de imaginarios se suele aludir a lo que la gente se imagina frente a una realidad planteada (Pintos, 1995).

Las creencias, aluden a proposiciones simples emitidas por las personas sobre un estado de cosas y que se identifican bajo la frase "Yo creo que..."; "se relacionan con el componente cognoscitivo e implican sistemas de conceptos respecto a la realidad, a partir de las cuales se derivan las distintas explicaciones sobre el mundo, se realizan predicciones y se da cuenta de los diferentes eventos" (Santoro, 1986, p.212). Las opiniones, mientras tanto, se refieren a la toma de posición o el concepto que es emitido por una persona frente a un estado de cosas que es controvertible socialmente (Moscovici, 1979) ${ }^{3}$.

En un intento por hacer frente a los anteriores retos conceptuales se debe profundizar en reflexiones de orden epistemológico y fenomenológico (entre otras tantas) que excederían el presente esbozo. Queda consignada; sin embargo, la dificultad que acarrea emprender un acercamiento conceptual sobre la idea de percepción en el ámbito académico, y cómo esta idea, casi sin discusión alguna, se considera clara y a punto de ser aceptada por el común de la gente, por investigadores y por las grandes firmas

3 En este sentido, los denominados "estudios de opinión" tiene entre sus objetivos "capturar" la toma de posición frente a cuestiones sociales que son consideradas como problemáticas. 
encuestadoras que ofrecen "Estudios de percepción" sin que en los mismos se revise, por lo menos a manera de introductoria, lo qué se entiende por ello dentro de su trabajo ${ }^{4}$.

Lo señalado hasta el momento pone al descubierto las dificultades que sobre el concepto de percepción se pueden dar y, adicionalmente, las semejanzas que este concepto puede tener con otras nociones. Sin embargo, y como lo señalan algunos especialistas, las diferencias:

no se pueden resolver apelando simplemente a unas definiciones esquemáticas, toda vez que las especificidades de estos conceptos derivan de unos marcos más amplios: de los modos de asumir el mundo social, su naturaleza, su comportamiento y sus dinámicas; al mismo tiempo, de los modos de conocer este mundo, que supone unas afirmaciones sobre el conocimiento, sobre las formas de conocer y sobre las finalidades de hacerlo (Serna, Oviedo \& Bravo, 2010, p.141).

En las diferencias entre la percepción y los conceptos señalados anteriormente, entran en juego elementos y factores culturales, ideológicos, e incluso aspectos psicológicos relacionados con estímulos físicos y sensoriales que complejizan aún más su intento de comprensión y diferenciación. Todos éstos, en tanto producciones mentales con origen en lo social, traen a su vez construcciones de la realidad que son disímiles junto con unas conductas particulares en el conjunto de relaciones sociales por parte de quienes realizan la interpretación, por cualesquiera de estos sistemas ideacionales. Específicamente, en el análisis de la percepción, se destaca el aporte que Merlau - Ponty (1993) hizo sobre la misma al concebirla como un proceso parcial; que se construye, significativamente, con el paso del tiempo y en este sentido como un ente relativo a las circunstancias históricas, sociales y culturales en donde la misma tiene lugar.

El trabajo que se presenta procura revisarla idea de percepción que se supone clara por todos y que; sin embargo, no es tal. Muestra de ello se presenta incluso a partir de los múltiples desarrollos teóricos que han tenido lugar en la psicología, disciplina que se ha encargado de profundizar con mucho más detalle en el estudio de la percepción ${ }^{5}$. De esta manera, y pese a las dificultades que el examen y comprensión del concepto soporta, por percepción, seguiremos a Vargas (1994) quien por ello entiende: "el proceso cognitivo de la conciencia que consiste en el reconocimiento, interpretación y significación para la elaboración de juicios en torno a las sensaciones obtenidas del ambiente físico y social" (p.48)

Para el caso concreto de los estudios de percepción pareciera que al hablar de ésta, se supone o se asume que todos (personas legas y novatas) conocen o saben qué se entiende por ello. Como ejemplo de esto, bastaría con traer a colación el famoso Estudio Colombiano de Valores y cuya introducción señala: "presentamos este estudio sobre cómo es el colombiano, cuáles son sus representaciones, creencias, actitudes e imaginarios" (Centro de Estudios Culturales, 2006, p.17). En lo sucesivo, en los tres tomos que recopilan los resultados no hay un apartado conceptual que se dedique a especificar en detalle qué se entiende por cada una de estas nociones.

4 Por supuesto, a partir de lo visto hasta el momento, lo que se entiende por percepción para $X$ e $Y$ estudio supondría un esfuerzo adicional en términos teóricos por parte de quienes diseñan los mismos pues esto exigiría aclarar la noción con la que se trabaja dentro del estudio así como el establecimiento de diferencias (psicológica, epistémica, etc.) que se tiene con otras propuestas definitorias. En definitiva, un esfuerzo adicional que muy seguramente explica por qué en estos estudios el concepto se asume como algo comprendido.

5 Para esto se puede ver el trabajo de sistematización de las teorías y las nociones de percepción en Vargas, 1994 y Oviedo, 2004. En este último, por ejemplo, se hace un detallado examen de la percepción desde la perspectiva de la Gestalt considerándola como un proceso fundamental de la actividad mental y en la que se ven involucradas actividades psicológicas como la memoria, el aprendizaje y el pensamiento, entre otras.

6 La autora a su vez, nos hace entender que es desde la psicología desde donde se ha impulsado el concepto de percepción social, resolviendo con éste la disyuntiva entre la percepción subjetiva y social señalada anteriormente, sosteniendo que toda percepción humana es social en tanto la misma se estructura a partir de factores del entorno y del ambiente; es decir, factores sociales y culturales. 
De esta manera, la percepción entendida como proceso cognitivo de la realidad servirá como base en la presente investigación para dar cuenta del examen de algunas respuestas sociales (juicios) ofrecidas por jóvenes universitarios de cara a lo sucedido (sensaciones) en el actual proceso de paz entre el gobierno nacional y la guerrilla de las FARC; y un eventual proceso de posacuerdo que sería generado como resultado de la mesa de negociación. Si bien el conflicto armado es un tema que concentra la atención por parte de diferentes sectores sociales, se considera útil, necesario y además interesante explorar las ideas que frente al mismo tiene la población universitaria, toda vez que este sector pareciera reproducir los sentimientos que la prolongación del mismo ha traído consigo en otros escenarios; a saber: un sentimiento de indiferencia ("el conflicto armado no es algo que tenga que ver directamente conmigo, no me afecta y en este sentido no me interesa"), de desconocimiento ("no se sabe en qué consiste el proceso de negociación o en qué va el mismo") o de prejuicio ("esto no servirá de nada") frente al tema.

Por otra parte, es en este sector donde se encuentran representadas una de las tantas motivaciones para migrar a la ciudad (búsqueda de oportunidades, acceso a la educación para el prestigio social y ascenso económico) y en el que se concentra una buena parte de la clase media, vital ésta para (según lo sostiene la teoría económica) la trasformación de las ciudades, guardando un punto concomitante con el proyecto de investigación, donde la tesis que le sustenta propone analizar las dinámicas que hacen del conflicto armado en Colombia, un hecho prolongado en el tiempo y espacio, pero a su vez acompañado de un modelo económico, político que ha proclamado la estabilidad institucional y el orden social, en especial en los sectores urbanos, donde la violencia bélica no ha impactado a buena parte de los sectores poblacionales.

\section{De la comprensión del conflicto al "boom" de las encuestas}

Han pasado los años en el que los grandes tratados sobre el conflicto armado en Colombia aparecían como referentes casi de culto para especialistas (Guzmán, Fals Borda \& Umaña, 2005; Pécaut, 1987; Comisión de Estudios de la Violencia, 1987). La dinámica de una sociedad impulsada por los avances de la técnica y la proliferación de espacios informativos en dispositivos digitales, ha impulsado estrategias que han pasado de seguir a los referentes clásicos para entender el conflicto, para entrar en una dinámica propia de la época, medir emociones y atraer un público disperso en cientos de ventanas atiborradas de publicidad, con un titular que capte su atención aunque sea por unos cuantos minutos (Lipovetsky, 2003).

En el olvido han quedado los programas de investigación de largo aliento, que contadas excepciones tienen resultados de impacto, en ocasiones producto de voluntades individuales y de dirigentes carismáticos y no de genuinos esfuerzos organizacionales, como ya sucedió en el año 2015 cuando el Consejo Latinoamericano de Ciencias Sociales (CLASO) denunció la ausencia de apoyo del Ministerio de Ciencia y Tecnología de Colombia (Colciencias), lo cual no sólo reflejó desidia estatal, sino indiferencia la difusión del conocimiento entre personas expertas de la región (Arcadia, 20 de noviembre).

En este contexto, las encuestas se erigen como el instrumento que mantiene el interés por un tema que se agotó en sus interpretaciones y en el que la sociedad prefirió voltear la espalda para solucionar sus necesidades de manera individual y ajena a cualquier proyecto de país. Las encuestas tienen aceptación porque tienen el poder de articular métodos cuantitativos y cualitativos en el momento de medir emociones, actitudes y mostrar contradicciones de las personas en la selección de sus preferencias. Por supuesto, no todas las encuestas tienen el mismo impacto e incidencia, pues esto depende de: 1. Credibilidad, 2. Poder Económico e Influencia Social y 3. Prestigio Institucional.

\section{- $\quad$ Credibilidad}

La Universidad de Los Andes ha tomado el liderazgo e iniciativa que le otorga su trayectoria académica para liderar programas que se proyectan como pioneros en la exploración de otras aristas, 
como es el caso del trabajo de Rettberg (2008) en el que se indaga sobre los impactos del conflicto en el sector empresarial, perspectiva arriesgada, pues la tendencia histórica ha mostrado cierta afinidad por los grupos sociales vulnerados. No obstante, la autora demuestra con suficiencia la importancia de vincular este sector si se quieren movilizar cambios en la estructura económica de un país en el que nunca fueron claros los acuerdos para el aprovechamiento de los recursos naturales, el fortalecimiento de las industrias y la distribución equitativa de la riqueza. En otras palabras, es un buen ejemplo de cómo las metodologías de las encuestas podrían contribuir a generar otras miradas al conflicto y no a reproducir sus lugares comunes.

En la misma línea, la Universidad de Los Andes realizó una alianza con el Centro de Memoria Histórica (2012) y presentaron una encuesta sobre lo que opinaban los colombianos respecto a la ley de justicia y paz (marco jurídico que sirvió para facilitar la desmovilización de grupos paramilitares). En la encuesta se resalta la selección de víctimas organizadas y especialistas como muestra poblacional, pero se comete una omisión en el momento de citar otros ejercicios de estadísticos, pasan por alto los realizados por los medios de comunicación, factor que puede ser involuntario, pero que desconoce el universo y el impacto de estas mediciones en la opinión pública, como ya se verá más adelante. Al final, el ejercicio no tuvo el impacto esperado y pasó casi inadvertido, tal vez porque como lo señaló el mismo gestor del proyecto, no hay una tradición en Colombia de salidas negociadas con grupos ilegales de derecha (Orozco, 2005).

No se puede decir que haya una política coherente en la promoción de programas universitarios que tengan ejercicios de medición sistemáticos sobre el conflicto y la construcción de paz, aunque se reconoce que hay esfuerzos por mantener el debate vivo y alentar el reto de una paz que transcurra del discurso a la concreción de retos posibles (Hernández, 2014). En esta dirección, los esfuerzos de investigadores han intentado hacer mediciones en sectores específicos que contribuyen a la búsqueda de salidas originales e interpretaciones que abran nuevas preguntas, como es el caso de Angulo, Ortiz y Pantoja (2014), quienes realizan la interpretación de las percepciones desde el enfoque de género, con la sorpresa de encontrar en las mujeres una actitud más escéptica frente al perdón y la reconciliación.

En los últimos años, se ha mostrado un generoso aumento de estudios en las regiones, en parte porque como ya se decía en páginas anteriores, las interpretaciones universales están agotadas, y por el creciente interés en mostrar distintas aristas de este fenómeno como lo muestra la investigación de Arias-López (2015) donde desde la especificidad de familias campesinas en el oriente antioqueño, devela cómo se va interiorizando el conflicto como uno más de los obstáculos que se tiene para sobrevivir, junto a los otros problemas estructurales, que la obsesión por el campo de batalla ignora.

Para finalizar, uno de los pocos estudios que abordan con seriedad las implicaciones de las percepciones y su relación con la psicología social, se encuentra en el trabajo de Alzate, Durán y Sabucedo (2009), quienes de entrada advierten sobre las limitaciones de teorías clásicas de las percepciones en las que se asume la realidad como una imposición objetiva y unívoca, para explicar la importancia de la sociedad civil en la reproducción o transformación del conflicto armado, sin necesidad de hacerse parte de la guerra.

\section{- Poder Económico e Influencia Social}

Los medios de comunicación son sin duda el actor que ha logrado disputarle el poder de persuasión a las instituciones tradicionales como la Escuela, el Estado y la Iglesia (Wilches, 2014). En las calles muchos reniegan de la ausencia de calidad en la información, los temas light o la presentación de novelas con temas que reflejan los antivalores, pero al final, buena parte de la información que circula termina siendo verificada en los grandes emporios mediáticos, así sea que sus interpretaciones sean tendenciosas. En relación con los conflictos armados Bonilla (2004) los cataloga como responsables de catapultar al conflicto y sus vías de solución como el gran elector de presidentes en Colombia, tesis 
que mantiene vigencia y de seguro la mantendrá hasta que una agenda más propositiva en los medios oriente lo contrario.

Mientras esto sucede, los medios tienen una chequera gruesa para contratar los servicios de empresas encuestadoras que, en cuestión de meses, elaboran sendos estudios que son publicados de manera ágil y con la ayuda de periodistas audaces en la elaboración de titulares "pomposos", como es el caso de la llamada "Gran Encuesta" (Napoleón Franco, 2015), resultado de una alianza demoledora como la que constituyen empresas de radio, televisión y prensa. Con la palabra "Gran" y el presidente de turno como el protagonista de los dardos y las críticas en preguntas que deciden de manera directa la legitimidad del gobernante con interrogaciones como: ¿Usted cree que el país va mejor, peor o igual?; las cuales de manera sutil son asociadas a preguntas relacionadas con el conflicto armado y las negociaciones de paz. El ejercicio logra el efecto de causar todo tipo de polémicas y discusiones sobre la metodología y tendencias de corto, mediano y largo plazo.

No obstante, llama la atención que hay una empatía entre las encuestas y la asociación del conflicto con las FARC como directos y en ocasiones únicos responsables. El efecto producido en las encuestas relacionadas con el conflicto originado por los grupos paramilitares no tiene las mismas reacciones, e incluso en la presentación es mucho más modesto, como sucedió con la encuesta publicada por la revista Semana, llamada, en los mismos términos “rimbombantes": el gran estudio de opinión (Napoleón Franco, 2007).

En este punto, se hace necesario que distintos grupos sociales influyan, para posicionarse en los espacios mediáticos donde se discuten estos temas, con el objetivo de hacer análisis que contribuyan a que la encuesta tenga una interpretación propositiva y no una visión destructiva. De lo que se trata entonces es de desplazar los imaginarios y quitar las miradas convencionales (Quiñones, 2009), donde se observa cómo un sector en apariencia informado como los jóvenes universitarios, puede llegar a caer en lugares comunes que los medios no matizan y que por el contrario la mayoría de veces reproducen de manera irresponsable y sin la mediación o sin las aclaraciones necesarias.

\section{- $\quad$ Prestigio Institucional}

La autoridad para opinar sobre un tema está respaldada por la entidad que patrocine el estudio. No es lo mismo que una encuesta sea presentada por un organismo de alcance internacional a que sea expuesta por una organización regional. No se trata de discriminación, el asunto es más pragmático y transversal a las dos variables ya expuestas: se trata de la capacidad, equipo de trabajo y proyección que tenga la encuesta. Este es el caso del Barómetro de las Américas, una iniciativa que supera los alcances nacionales y está respaldada por la conjunción de esfuerzos y personalidades que avalan sus resultados y que ocupan ya el lugar de fuente informativa para cualquier investigador que intente medir o hacer un rastreo sobre determinadas actitudes sociales frente a temas neurálgicos como el desempleo, justicia, corrupción y cultura política.

El ejercicio realizado por el Observatorio de la Democracia y la Universidad de los Andes de manera bianual desde el año 2004 da muestras de un giro interesante en los temas top de la agenda nacional. Mientras entre los años 2004 y 2010 se intentaba indagar por la cultura política -en parte agenciado por los impactos de la figura de la reelección presidencial en el sistema político- en el 2012 y 2014, el asunto por obvias razones viró hacia el proceso de paz. A pesar de la rigurosidad del instrumento y la explicación detallada de la metodología, el ejercicio a diferencia de años anteriores se queda corto en su fase interpretativa, y se pasa al extremo de los análisis eufóricos de los medios de comunicación, al quedarse con posiciones tímidas en las que no asumen la preocupación de ver que determinados sectores poblacionales - no toda la sociedad- piensen que una negociación se realiza sin generar ninguna concesión, como se expone en las consideraciones finales del reporte.

El mismo caso aparece al leer el informe de la Contraloría General de la República (2014) en la que se realiza una encuesta a las víctimas del conflicto armado. Luego de aplicar una herramienta 
compleja para recopilar los datos, la presentación se limita a realizar unas recomendaciones predecibles, que a decir verdad, hubieran podido exponerse, sin necesidad de haber realizado un trabajo de semejante magnitud, del cual se pueden arrojar resultados más interesantes o para ir más allá, acciones que desencadenen en la formulación de políticas públicas integrales y que atiendan de manera gradual pero contundente a las víctimas.

Por último, se encuentran referencias de organizaciones como la Fundación Social y el Centro Internacional de Justicia Transicional (2006), quienes asumieron el riesgo de titular las publicaciones de las encuestas como un ejercicio de percepciones y opiniones. Sin embargo, el trabajo investigativo es demasiado ligero al relacionar sin ningún sustento conceptual las percepciones a las opiniones, y sin definir un lugar teórico desde dónde abordar el debate. En el estudio en mención, se da por sentado que las percepciones son entendidas por cualquier lector, cuando es un concepto que desde disciplinas como la psicología, la ciencia política o la economía ha tenidos distintos abordajes, los cuales pueden determinar el sentido de una encuesta.

También es extraño que en la fase de interpretación se caiga en la redundancia de indicar de manera escrita lo que ya está reflejado en los gráficos (por ejemplo, si una gráfica señala que el 60\% de las personas está de acuerdo con que se combata la guerrilla y que esto se redacte como: el 40\% de las personas no están de acuerdo con que se combata a la guerrilla), lo cual le quita fuerza a la interpretación y las tendencias, factores que son fundamentales al asumir los resultados del instrumento aplicado. En este caso, el análisis podría asumir una metodología holística en la que se tome una posición que defina el criterio de personas expertas e inviten a profundizar la discusión en un ambiente de respeto por las ideas, pues en ocasiones se llega a los debates agenciados por los intereses de poder o los comités de aplausos, ambos caracterizados por la ausencia de propuestas que integren otras metodologías de carácter cualitativo y cuantitativo.

\section{2. ¿Cómo se desarrolló el estudio de percepción del conflicto armado y el posacuerdo en jóvenes universitarios?}

Con el reconocimiento de la complejidad del tema seleccionado, se realizaron entrevistas personales a 500 estudiantes universitarios, hombres y mujeres, cuyas edades oscilaban entre los 16 y 30 años pertenecientes a diferentes carreras y semestres de universidades públicas y privadas en Bogotá (Colombia). Las encuestas se aplicaron de manera aleatoria durante el mes de abril de 2015. La distribución de la muestra fue la siguiente:

\begin{tabular}{lcc}
\hline Institución Educativa de Educación Superior & Tipo de institución & No. de entrevistas \\
\hline Universidad Distrital Francisco José de Caldas & Pública & 110 \\
Universidad Nacional de Colombia & Pública & 70 \\
Universidad Pedagógica Nacional de Colombia & Pública & 70 \\
Fundación Universitaria Konrad Lorenz & Privada & 34 \\
Fundación Universitaria Los Libertadores & Privada & 36 \\
Corporación Unificada Nacional & Privada & 40 \\
Universidad de La Salle & Privada & 70 \\
Universidad de Los Andes & Privada & 70 \\
\hline TOTAL & & 500
\end{tabular}

Las características generales de la población en la cual se realizó el estudio se encuentran resumidas en las siguientes gráficas: 

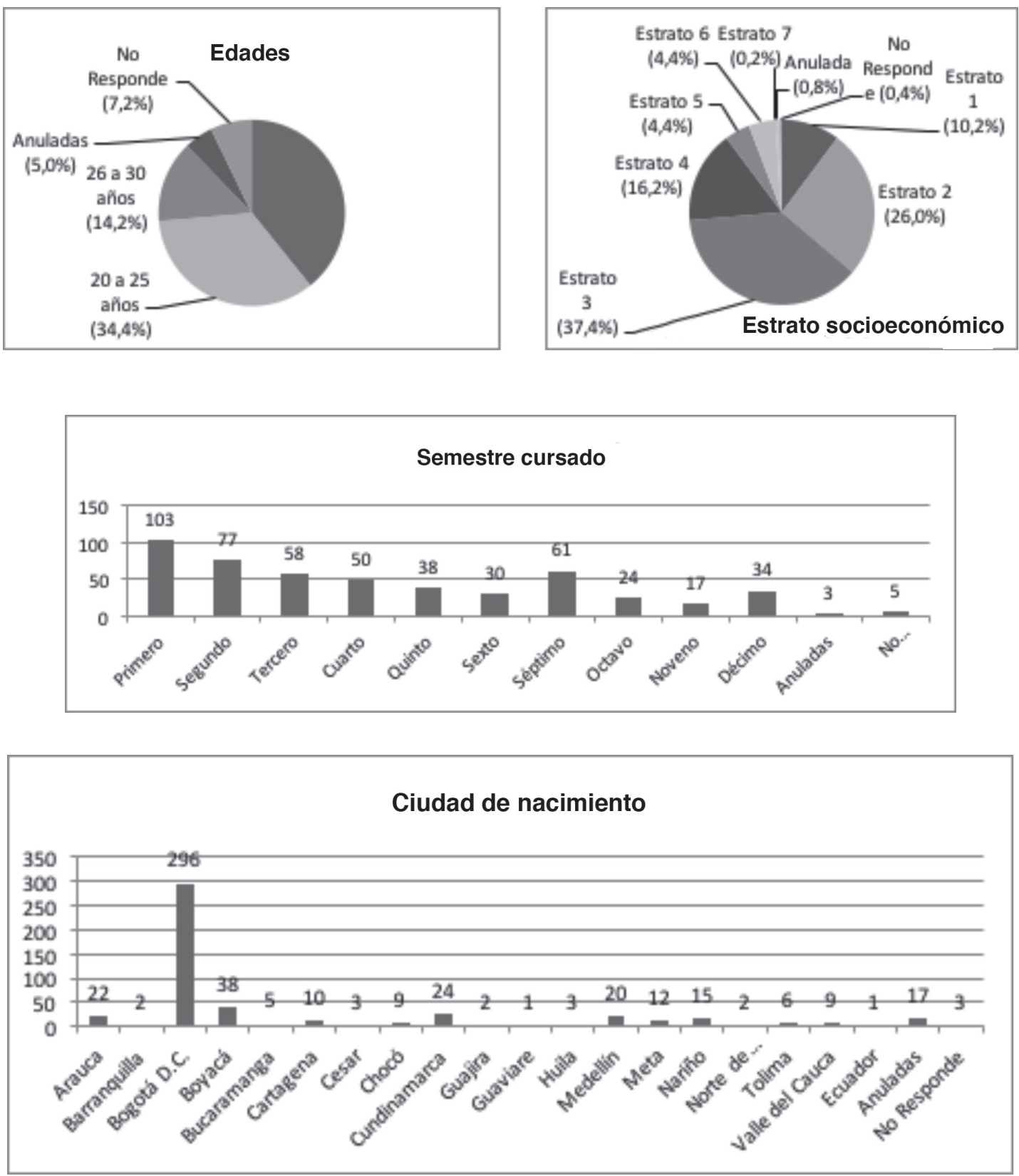

La encuesta estuvo conformada por 20 preguntas (ver el anexo al final del artículo en el que se presenta la encuesta en su totalidad), distribuidas en cinco partes correspondientes a las temáticas sobre las cuales se realizaría el trabajo de percepción de la siguiente manera: 


\begin{tabular}{llc}
\hline Sección & Temática & Número de preguntas \\
\hline A & Conocimiento general sobre el proceso de paz en Colombia & 1 \\
B & Refrendación & 5 \\
C & Reconciliación & 5 \\
D & Conflicto urbano & 5 \\
E & Actores sociales & 4 \\
\hline
\end{tabular}

\section{- $\quad$ Análisis de resultados}

En esta sección, se analizarán las tendencias de los resultados, siguiendo como estrategia metodológica, las forma cómo los encuestados respondieron las preguntas, de acuerdo al nivel de dificultad de las preguntas, y en la que se llega a la siguiente hipótesis: los encuestados tienden a sentirse más cómodos con encuestas de opciones cerradas y bipolares, a enfrentar preguntas de opción múltiple, categorización de variables o interpretación de hechos coyunturales.

\section{Preguntas bipolares}

Las preguntas más fáciles de responder son las que conducen a la polarización, son directas, no abren escenarios para discutir y no provocan reflexión. Este es el caso de las siguientes preguntas, en las que el número de respuestas anuladas o categorizada según la variable "No saben/No responden", no tienen un porcentaje significativo.

¿De alguna manera usted se considera víctima o ha recibido impactos directos o indirectos del conflicto armado?

\begin{tabular}{lcr}
\hline \multicolumn{1}{c}{ Respuesta } & $\begin{array}{c}\text { Número de } \\
\text { respuestas }\end{array}$ & \% \\
\hline SÍ & 200 & $40,0 \%$ \\
NO & 285 & $57,0 \%$ \\
Anuladas & 10 & $2,0 \%$ \\
No Responde & 5 & $1,0 \%$ \\
TOTAL & 500 & $100,0 \%$ \\
\hline
\end{tabular}

Usted, como joven universitario, ¿cree posible el perdón y la reconciliación entre el conjunto de la sociedad colombiana y los miembros desmovilizados de las FARC?

\begin{tabular}{lrr}
\hline \multicolumn{1}{c}{ Respuesta } & $\begin{array}{c}\text { Número de res- } \\
\text { puestas }\end{array}$ & $\%$ \\
\hline SÍ & 288 & $57,6 \%$ \\
NO & 156 & $31,2 \%$ \\
Anuladas & 30 & $6,0 \%$ \\
No Responde & 26 & $5,2 \%$ \\
TOTAL & 500 & $100,0 \%$ \\
\hline
\end{tabular}

¿Está usted de acuerdo con que el gobierno Santos consulte a la sociedad colombiana el contenido de un acuerdo con la guerrilla de las FARC?

\begin{tabular}{lcr}
\hline \multicolumn{1}{c}{ Respuesta } & $\begin{array}{c}\text { Número de } \\
\text { respuestas }\end{array}$ & $\%$ \\
\hline SÍ & 406 & $81,2 \%$ \\
NO & 62 & $12,4 \%$ \\
Anuladas & 22 & $4,4 \%$ \\
No Responde & 10 & $2,0 \%$ \\
TOTAL & 500 & $100,0 \%$ \\
\hline
\end{tabular}

¿Cuál es la importancia que generaría para su vida cotidiana un acuerdo de paz entre el Estado colombiano y la guerrilla de las FARC?

\begin{tabular}{lrr}
\hline \multicolumn{1}{c}{ Respuesta } & \multicolumn{2}{c}{$\begin{array}{c}\text { Número de } \\
\text { respuestas }\end{array}$} \\
\hline Nada importante & 56 & $11,2 \%$ \\
Poco importante & 93 & $18,6 \%$ \\
Importante & 208 & $41,6 \%$ \\
Muy importante & 119 & $23,8 \%$ \\
Anuladas & 13 & $2,6 \%$ \\
No Responde & 11 & $2,2 \%$ \\
TOTAL & 500 & $100,0 \%$ \\
\hline
\end{tabular}




\section{Preguntas con categorización de variables}

Este tipo de preguntas fueron las que más dificultad ofrecieron en su respuesta (lo cual se evidenció en el tiempo que tomó su diligenciamiento) en virtud de dos elementos particulares: la utilización de una escala (pues esto exige un nivel mayor de concentración y reflexión) y, en algunas oportunidades, el reconocimiento que tras la pregunta misma los jóvenes llegasen a tener sobre las instituciones indagadas frente al proceso de paz y el conocimiento de personalidades con influencia sobre la vida política del país.

Establezca de 1 a 9, siendo 1 (mayor incidencia) y 9 (menor incidencia), el nivel de incidencia de las siguientes instituciones en caso de darse un acuerdo de paz entre el gobierno Santos y la guerrilla de las FARC:

\begin{tabular}{lccccccccccc}
\hline Concepto/ Importancia & $\mathbf{1}$ & $\mathbf{2}$ & $\mathbf{3}$ & $\mathbf{4}$ & $\mathbf{5}$ & $\mathbf{6}$ & $\mathbf{7}$ & $\mathbf{8}$ & $\mathbf{9}$ & Anuladas & TOTAL \\
\hline Academia & 57 & 43 & 42 & 33 & 26 & 44 & 35 & 30 & 48 & 142 & 500 \\
Medios de comunicación & 41 & 30 & 49 & 50 & 47 & 38 & 49 & 30 & 24 & 142 & 500 \\
Empresarios & 20 & 37 & 24 & 35 & 37 & 42 & 49 & 78 & 36 & 142 & 500 \\
Iglesia & 20 & 14 & 21 & 21 & 19 & 34 & 44 & 54 & 131 & 142 & 500 \\
Organizaciones Sociales & 34 & 33 & 59 & 46 & 55 & 45 & 34 & 32 & 20 & 142 & 500 \\
Rama Judicial & 19 & 31 & 44 & 64 & 56 & 61 & 24 & 36 & 23 & 142 & 500 \\
Congreso de la República & 31 & 51 & 54 & 54 & 46 & 28 & 38 & 26 & 30 & 142 & 500 \\
Fuerzas Armadas & 48 & 74 & 49 & 31 & 27 & 45 & 21 & 35 & 28 & 142 & 500 \\
Víctimas & 85 & 41 & 48 & 36 & 28 & 37 & 27 & 17 & 39 & 142 & 500 \\
\hline
\end{tabular}

Establezca de 1 a 10, siendo 1 (mayor incidencia) y 10 (menor incidencia), el nivel de incidencia de los siguientes personajes en caso de darse un acuerdo de paz entre el gobierno Santos y la guerrilla de las FARC:

\begin{tabular}{lcccccccccccc}
\hline Concepto/ Importancia & $\mathbf{1}$ & $\mathbf{2}$ & $\mathbf{3}$ & $\mathbf{4}$ & $\mathbf{5}$ & $\mathbf{6}$ & $\mathbf{7}$ & $\mathbf{8}$ & $\mathbf{9}$ & $\mathbf{1 0}$ & Anuladas & TOTAL \\
\hline Juan Manuel Santos & 221 & 42 & 10 & 3 & 15 & 2 & 4 & 2 & 18 & 19 & 164 & 500 \\
Gustavo Francisco Petro Urrego & 14 & 58 & 48 & 50 & 40 & 35 & 30 & 27 & 18 & 16 & 164 & 500 \\
Martha Lucía Ramírez & 2 & 29 & 35 & 31 & 55 & 46 & 51 & 35 & 20 & 32 & 164 & 500 \\
Antanas Mockus Šivickas & 14 & 21 & 28 & 38 & 36 & 44 & 48 & 35 & 49 & 23 & 164 & 500 \\
Álvaro Uribe Vélez & 32 & 71 & 53 & 31 & 32 & 25 & 19 & 21 & 19 & 33 & 164 & 500 \\
Piedad Córdoba & 8 & 22 & 58 & 62 & 32 & 58 & 26 & 25 & 17 & 28 & 164 & 500 \\
Antonio Navarro Wolff & 14 & 25 & 39 & 47 & 20 & 36 & 48 & 47 & 34 & 26 & 164 & 500 \\
Alejandro Ordoñez & 7 & 13 & 25 & 31 & 46 & 37 & 34 & 67 & 37 & 39 & 164 & 500 \\
Fidel Castro & 10 & 20 & 32 & 20 & 31 & 45 & 29 & 28 & 72 & 49 & 164 & 500 \\
Barack Obama & 15 & 27 & 30 & 22 & 20 & 18 & 22 & 22 & 49 & 50 & 164 & 500 \\
\hline
\end{tabular}




\section{Pregunta abierta (con opciones de respuesta)}

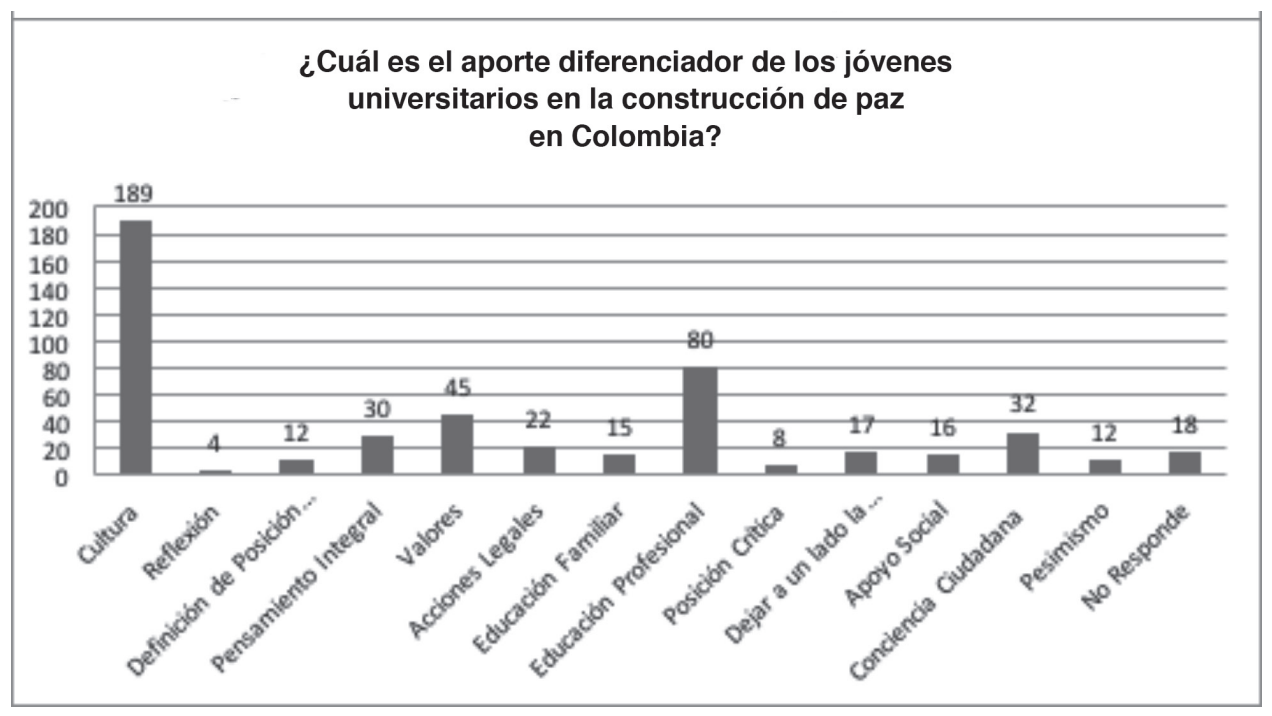

Las respuestas anteriores llaman la atención, pues si el porcentaje más alto hace relación al aporte que desde la cultura pueden dar los jóvenes. ¿Cómo leer esto en relación con la "cultura política” y el nivel de conocimiento que contrasta con las respuestas de la anterior sección? Ciertamente, esto constituye una paradoja dentro de lo que los jóvenes dicen aportar y lo que, efectivamente, pueden aportar. Si a esto se suma el tema de educación profesional y conciencia ciudadana, el resultado es mucho más paradójico. Por otra parte, hay ciertas características que "se creen" afincadas en los jóvenes (valores, posición crítica, no ser indiferentes, conciencia ciudadana). Sin embargo, el proceso de formación y con ello, el acceso a la cultura es un elemento determinante en lo que podría ser su rol en la sociedad. ¿Pero están formándose efectivamente para ello?

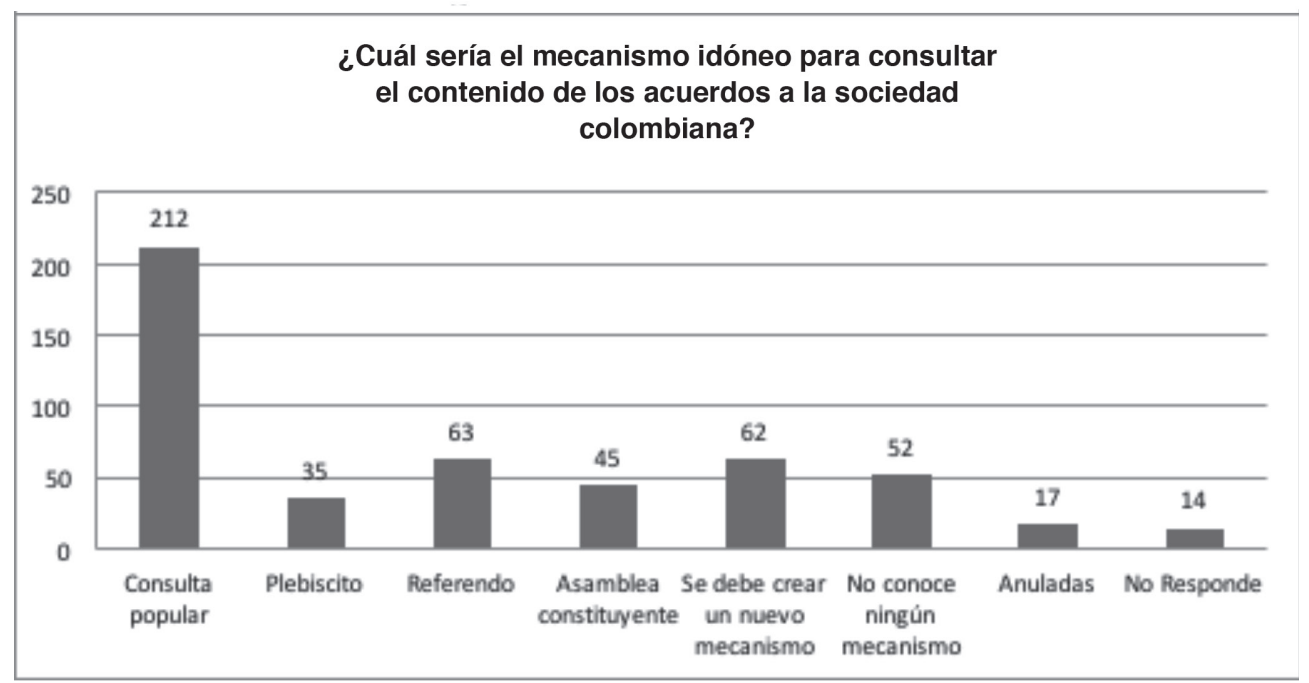

Los anteriores resultados nos plantean una pregunta adicional: ¿Cuál es el nivel de conocimiento de los jóvenes sobre nuestra Constitución Política? La pregunta parte del supuesto que los jóvenes conocen los mecanismos constitucionales y las diferencias presentes entre los mismos, por tanto, se hace 
posible identificar qué es lo que no satisface de los mismos. ¿Qué otros mecanismos proponen? ¿Cuáles serían las otras alternativas? ¿Qué tanta cultura política hay sobre el tema? Son temas que quedan por fuera de la investigación; sin embargo, valdría la pena determinar en futuras investigaciones hasta qué punto las respuestas obedecerían más a un "aparentar" que se sabe frente a un "saber efectivo" por lo que se está indagando.

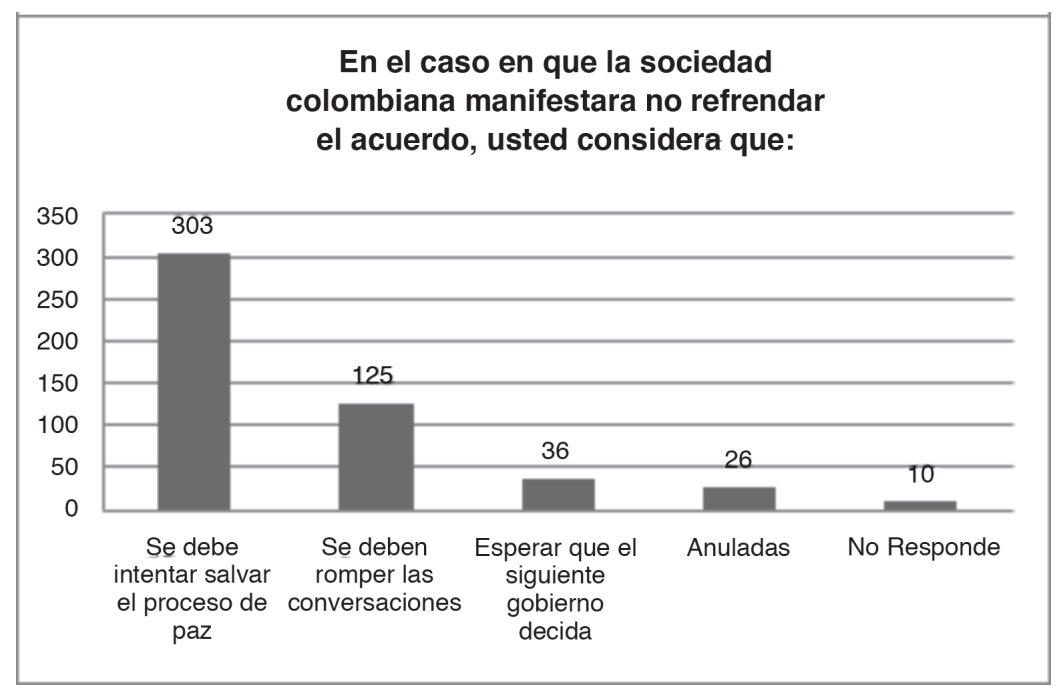

El anterior resultado es revelador: de todas maneras hay esperanza en el proceso, y se mantiene la idea de que ésta, la coyuntura, es la última oportunidad para lograr la paz (sea lo que sea que se entienda por este concepto).

En caso de que se consulte a la sociedad colombiana el contenido de los acuerdos con la guerrilla de las FARC, usted apoyaría los mismos si se cumpliera con una de estas condiciones:

\begin{tabular}{lcc}
\hline Respuestas & Número & $\%$ \\
\hline Las FARC pidieran perdón y pagarán cárcel & 149 & $29,8 \%$ \\
Hubiera un cese bilateral al fuego & 174 & $34,8 \%$ \\
El gobierno garantizara participación política de las FARC & 75 & $15,0 \%$ \\
Otra, ¿cuál? & 50 & $10,0 \%$ \\
Anuladas & 42 & $8,4 \%$ \\
No Responde & 10 & $2,0 \%$ \\
TOTAL & 500 & $100,0 \%$ \\
\hline
\end{tabular}

La anterior tabla plantea que para los jóvenes universitarios la negociación se entiende bajo el silenciamiento de los fusiles de ambas partes. Se apoya un proceso y lo acordado en el mismo, siempre y cuando no se combata. Antes de garantizar cualquier participación en política, los señores que hacen la guerra deben resarcir el daño realizado a la sociedad donde la cárcel no se descarta como única opción como lo revela el siguiente resultado. 


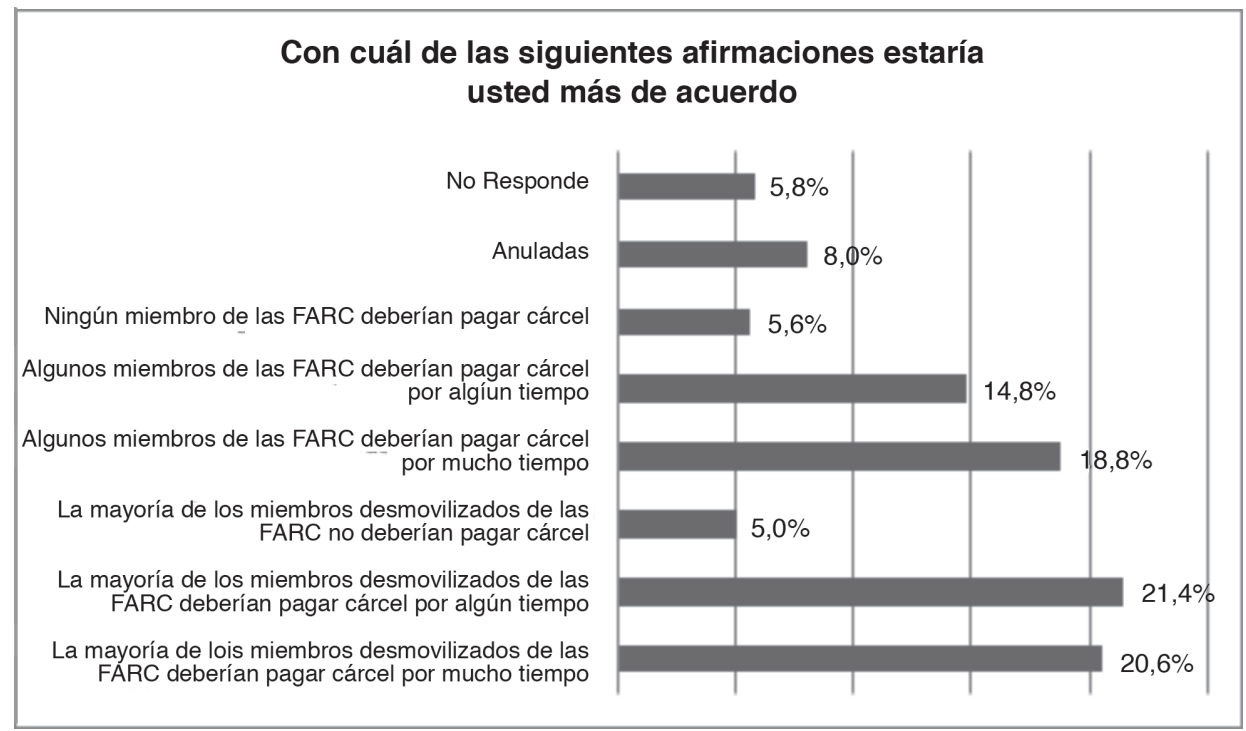

La cárcel pareciera concebirse como la única alternativa para pensar mecanismos de aplicación de justicia. ¿Dónde queda la justicia transicional? La pregunta no abre esta posibilidad pero es algo que debe pensarse al momento de hablar de una "pedagogía para la paz" durante el proceso y un eventual escenario de posacuerdo.

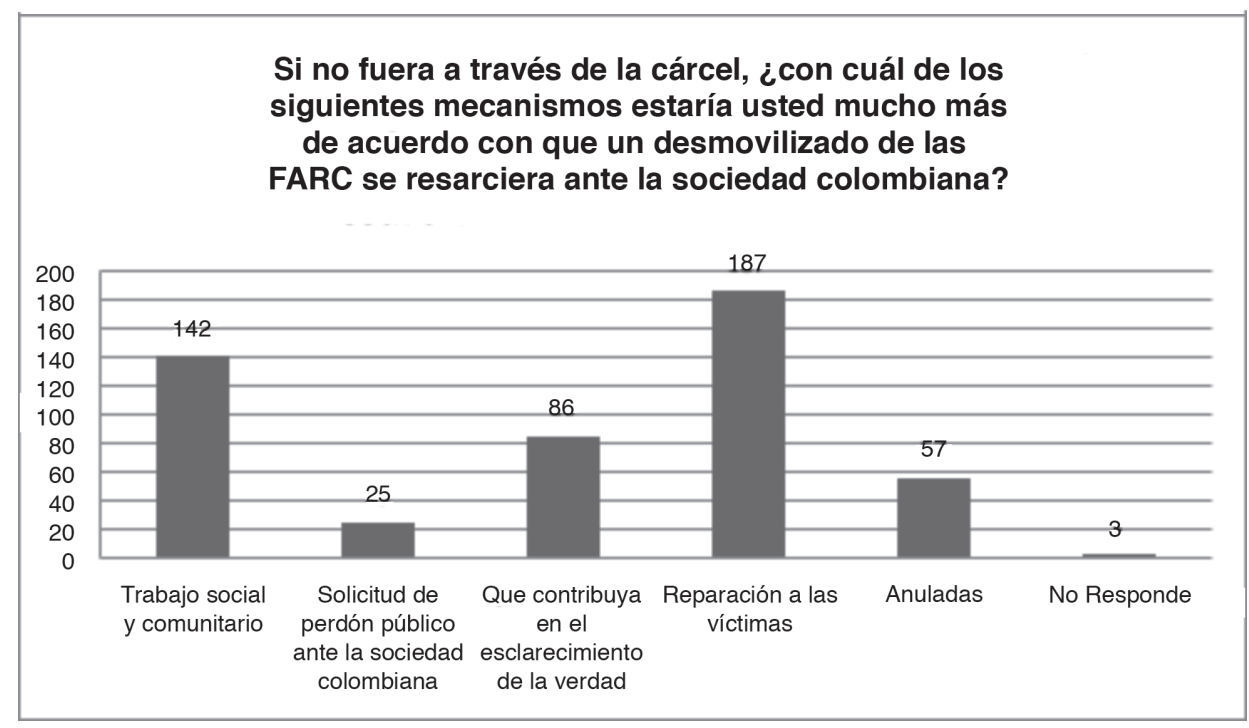

¿Qué entienden los jóvenes por reparación a las víctimas? ¿Cuentan los jóvenes con el conocimiento suficiente de las diferentes vías de reparación contempladas? (administrativa, simbólica, etcétera.). El mal que se le hizo a la sociedad debería ser retribuido mediante el trabajo y la verdad (ad portas de la conformación de una comisión); diálogo este aún pendiente. 


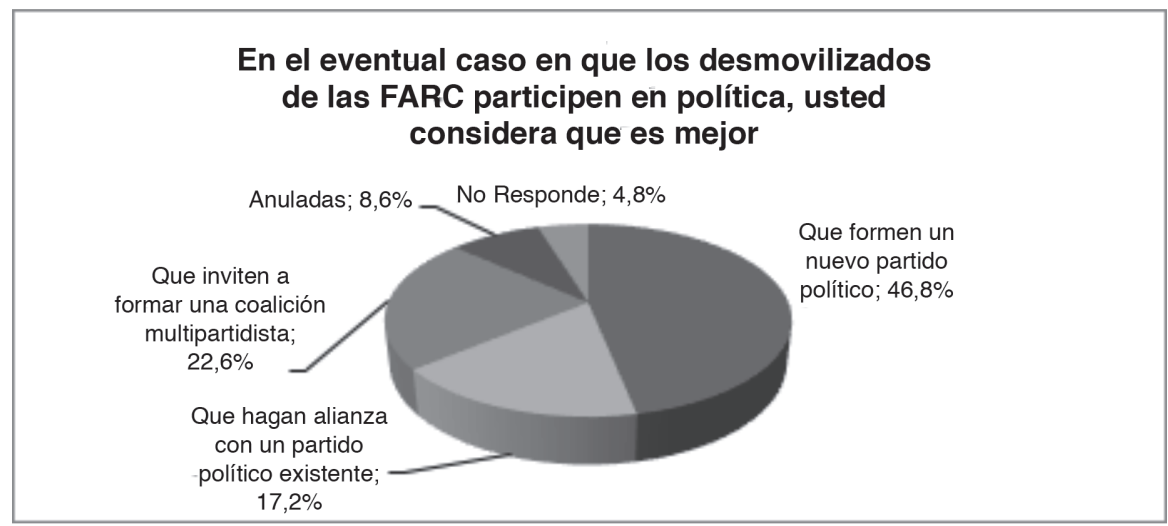

La esperanza en los partidos tradicionales es puesta en entredicho por las personas jóvenes; frente a esto, dos opciones: formar un nuevo partido que deje de lado las prácticas clientelistas y corruptas de los partidos actuales -se podría hablar de un desencanto hacia los partidos- o, la esperanza hacia una nueva coalición que "recupere" lo mejor de los mismos en la búsqueda y consolidación de la paz.

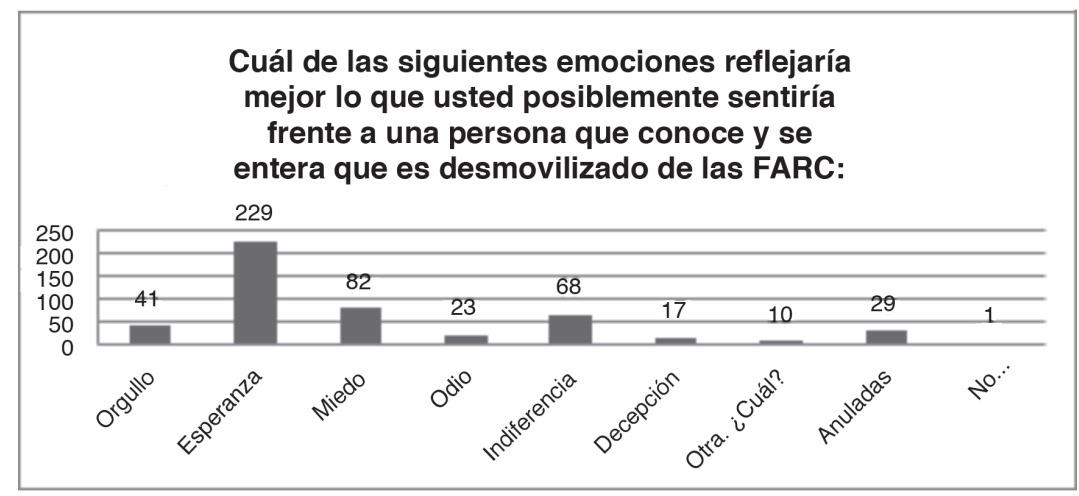

La pregunta sobre emociones frente a desmovilizados tuvo dificultades en su sistematización; sin embargo, la esperanza es lo último que se pierde y esto se encuentra reflejado en las respuestas. Detrás de un desmovilizado se encuentra la idea de una persona que pese a que el miedo continúe reinante en el ambiente existe la posibilidad de un cambio.

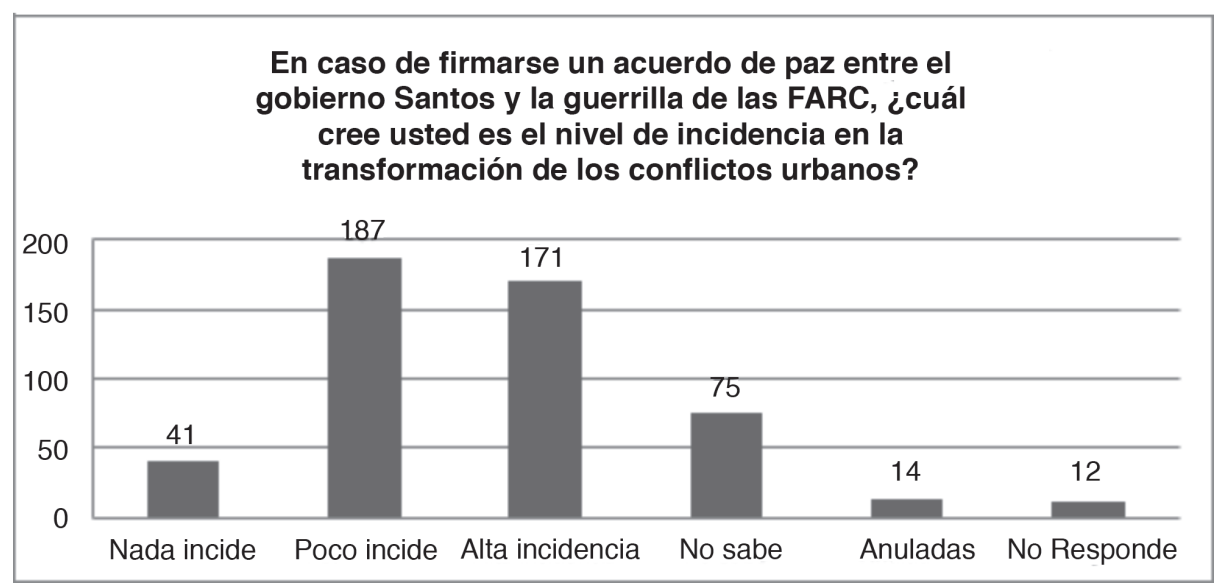


Lo urbano no es un referente para pensar el conflicto armado; pareciera que se mantienen las fronteras "centro"-"periferia", en donde el conflicto de la periferia no ataca o afecta el centro, pero las decisiones que se toman desde éste si cuentan con incidencia sobre aquella. El centro político y la periferia campesina parecieran ser hoy dos realidades mutuamente excluyentes aunque no necesariamente independientes al momento de pensar el futuro del país en términos de incidencia de conflictividad a nivel urbano.

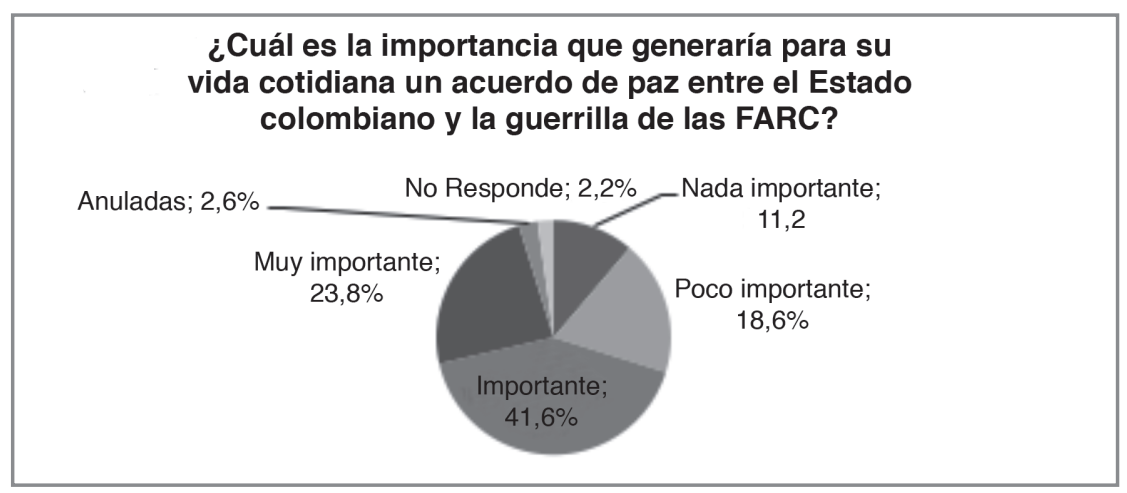

Con todas y sus dificultades y contradicciones, un acuerdo de paz es importante para la población de jóvenes. Es mejor vivir en paz que en guerra y de esto dan constancia estas respuestas.

\section{Balance, reflexiones y recomendaciones}

Después de realizado este ejercicio varias son las reflexiones en lo concerniente al diseño, aplicación, recolección, análisis y sistematización de la información de trabajos de este orden.

El primer elemento y sobre el cual se llamó la atención en la primera parte de este escrito consiste en que se hace necesario enmarcar y contextualizar los estudios que se hagan a nivel de percepción; es decir, los estudios sobre percepción deberían preocuparse por clarificar qué se entiende por la misma, pues una es la idea de percepción a partir de lo sensorial, otra a partir de la psicología y otra más la que se establece desde la fenomenología; y así, sucesivamente. Al corresponder la percepción a un sistema ideacional bastante amplio en el que se entrecruzan visiones complementarias procedentes de diferentes ámbitos del conocimiento, ameritaría de manera rigurosa, o por lo menos en el campo de lo descriptivo, clarificar lo que por este concepto se entiende junto con los conceptos fundamentales sobre los que se encontrará soportada la investigación.

Este procedimiento, que pareciera ser uno de los principios básicos fundamentales en la investigación, suele dejarse de lado ante la premura, y el interés por llamar la atención (muchas veces por intereses mediáticos) sobre los resultados más que sobre la manera en que estos resultados fueron obtenidos. La primera recomendación consistiría en aclararlos marcos conceptuales sobre los cuales encuestas de este orden tendrán desarrollo. Esto pareciera hacerse presente en las investigaciones que se desarrollan en la academia; no lo es tanto en los estudios elaborados por los medios de comunicación y pareciera invisible en los desarrollos de las grandes cadenas encuestadoras y que, históricamente, han abanderado el tema de estudios de percepción sobre diferentes problemáticas.

El segundo elemento apuntaría a que los resultados de los trabajos de percepción no solamente fuesen presentados sino que además, los mismos deben estar acompañados de elementos de autocrítica que permitan cualificar los instrumentos diseñados para la aproximación a las problemáticas sociales. No solamente se trata de mostrar el margen de error, sino de señalar las dificultades y errores que se identificaron tanto en el ejercicio de diseños de instrumentos como en la aplicación y el análisis de los resultados. En el trabajo que aquí se presenta, aunque tímidamente, se han abordado cuestiones de este orden, pero ya el hacerlo constituye un avance. 
Los trabajos estadísticos no deberían culminar con la presentación de los resultados; por el contrario, este debería ser punto de partida para impulsar investigaciones, centrada a partir de las reacciones y actitudes que traen consigo los hallazgos mismos. Se trataría, por plantearlo en otros términos, de realizar un abordaje más profundo obre las conclusiones de un ejercicio de percepción para, con esto, proveer de análisis que, nuevamente, no se pueden quedar en lo mediático sino procurar ir más allá de esto.

En este orden de ideas, los impactos de los resultados de los ejercicios de percepción sobre problemáticas sociales deberían socializarse con quienes son los principales actores que dinamizan o hacen parte de estas problemáticas (instituciones, actores, entre otros) y quienes son a su vez objeto de indagación del ejercicio aplicado. Aunque útiles los resultados para el robustecimiento y crecimiento de la academia, la descentralización del discurso de lo que se hace en la misma es fundamental para que la universidad tenga el impacto social que se le ha venido reclamando desde tiempo atrás. Si las instituciones universitarias se consideran como nichos de importancia en la reflexión a propósito del mejoramiento de las condiciones sociales la oportunidad está dada en las acciones, ejercicios y dinámicas que se generen a partir de los resultados obtenidos.

Por último, la educación para la paz debería entenderse como una oportunidad para dar trámite al conjunto de contradicciones, ideas, y aspectos que quedan abiertos y reflejados en este tipo de ejercicios. Se debe partir de un conocimiento de los hechos sociales (es cierto), es decir, se requiere un medio cognitivo que permita el acercamiento entre los jóvenes con la realidad; sin embargo, ello no es suficiente. Suscitar un pensamiento crítico continuará siendo un reto abierto y permanente. Pero para esto se hace necesario trabajar en la forma en que los jóvenes "traducen" la realidad social y brindarles las herramientas necesarias para evaluar las fuentes a partir de las cuales se nutren de esa realidad social (medios, amigos, familia, redes sociales y demás fuentes.).

\section{Bibliografía}

Alzate, Mónica, Durán, Mar \& Sabucedo, José Manuel. (2009). Población civil y transformación constructiva de un conflicto armado interno: aplicación al caso colombiano. Universitas Psychologica, 3 (8), 703-720.

Angulo, María Camila, Ortiz, Andrés Mauricio \& Pantoja, Sebastián. (2014). Análisis de las percepciones de los colombianos sobre el proceso de paz y el posconflicto desde una perspectiva de género. Colombia Internacional, 80, 220-233.

Arias-López, Beatriz Elena. (2015). Vida cotidiana y conflicto armado en Colombia: los aportes de la experiencia campesina para un cuidado creativo. Aquichan, 15 (2), 239-252.

Araya, Sandra. (2002). Las representaciones sociales: Ejes teóricos para su discusión. Cuaderno de Ciencias Sociales, 127. Costa Rica: Flacso.

Bonilla, Jorge Iván. (2004). Medios de comunicación, opinión pública y conflicto armado. En Anuario social, político y económico de Colombia (pp. 9-30). Bogotá: FESCOL, IEPRI, Nueva Sociedad.

Centro de Estudios Culturales. (2006). Nuestra identidad. Estudio colombiano de valores. Bogotá, Colombia: Panamericana, S.A.

Centro de Memoria Histórica, Fundación Social, Organización Internacional para las Migraciones (OIM), Unidad para la Atención y Reparación Integral a las Víctimas, Universidad de Los Andes. (2012). Encuesta Nacional ¿Qué piensan los colombianos después de siete años de justicia y paz? Bogotá: Publicaciones Semana.

Comisión de Estudios sobre la Violencia (1987). Colombia: violencia y democracia. Bogotá: Universidad Nacional de Colombia.

Consejería en proyectos, Fundación social, ICTJ. (2006). Percepciones y opiniones de los colombianos sobre justicia, verdad, reparación y reconciliación. Colombia: Géminis.

Contraloría General de la República. (2014). Informe de avance de la Encuesta Nacional de Víctimas_ CGR-2013 (ENV_CGR-2014) a la Corte Constitucional. Bogotá: autor. 
García, Ricardo. (2014). Teorías y tramas del conflicto armado en Colombia. Bogotá: Universidad Distrital Francisco José de Caldas.

Guzmán, Germán, Fals Borda, Orlando \& Umaña, Eduardo. (2005). La violencia en Colombia. Bogotá: Taurus.

Hernández, Mauricio. (2014). La paz, el reto mayor para la construcción de país. Bogotá: Universidad Distrital Francisco José de Caldas.

Ipsos Napoleón Franco, Alianza de Medios, RCN Radio, RCN Televisión, La FM y Revista Semana. (2015). Colombia Opina Abril de 2015. Medición 11. Bogotá: autor.

Ipsos Napoleón Franco, revista Semana. (2007). Gran encuesta sobre parapolítica. Bogotá: autor.

Merleau - Ponty, Maurice. (1993). Fenomenología de la percepción. Barcelona, España: Planeta De Agostini, S.A.

Ministerio de Educación Nacional. (2012). Capital humano para el avance colombiano. Boletín Educación Superior, 20, 1-20.

Moscovici, Serge. (1979). El psicoanálisis, su imagen y su público. Buenos Aires, Argentina: Huemul S.A.

Observatorio de la Democracia, Universidad de Los Andes (2015). Barómetro de las Américas.. Recuperado de http://obsdemocracia.org/datos/page/barometro

Orozco, Iván. (2005). Reflexiones impertinentes sobre la Memoria y el Olvido, sobre el Castigo y la Clemencia. En Rettberg, Angélika. (Comp.), Entre el perdón y el paredón: preguntas y dilemas de la justicia transicional (pp. 54-71). Bogotá: Universidad De Los Andes.

Oviedo, Gilberto. (2004). La definición del concepto de percepción en psicología con base en la teoría Gestalt. Revista de Estudios sociales, (18), 89-96.

Pécaut, Daniel. (1987). Orden y violencia en Colombia 1930-1953. Bogotá: CEREC, Siglo Veintiuno.

Pintos, Juan Luis. (1995). Los imaginarios sociales. La nueva construcción de la realidad social. Bilbao: Sal Terrae.

Pintos, Juan Luis. (2006). Comunicación, construcción de realidad e imaginarios sociales (pp.23-66). Proyectar imaginarios. Autores varios. Bogotá: Quebecor World Bogotá, S.A.

Quiñones, Beatriz. (2009). Observar, incidir, participar. Bogotá: Universidad Nacional de Colombia.

Rettberg, Angélika. (2008). Explorando el dividendo de la paz: impactos del conflicto armado en el sector privado colombiano. Bogotá: Universidad de Los Andes.

Rivas, Angela. (2010). Empresas, Derechos Humanos y Entornos Complejos. Colombia: el peor y el mejor de los mundos. En Prandi, María \& Lozano, Josep (Eds.), La RSE en contextos de conflicto y postconflicto: de la gestión del riesgo a la creación de valor (pp. 103-115). Barcelona: Escola de Cultura de Pau (UAB), Instituto de Innovación Social (ESADE).

Santoro, Eduardo. (1986). Efectos de la comunicación. Quito, Ecuador: Ciespal.

Serna, Adrián; Oviedo, Álvaro; Bravo, Fernando. (2010). Creencia, sistema de creencias y poder simbólico. Una propuesta para indagar los sistemas ideacionales desde la Investigación Social Interdisciplinaria. En Varios (2010), Desafíos en Estudios Sociales e interdisciplinariedad (pp. 135 - 154). Bogotá, Colombia: Antropos.

Vargas, Luz. (1994). Sobre el concepto de percepción. Alteridades, 4 (8), 47-53.

Wilches, Jaime. (2014). ¿Y educar para qué? Representaciones mediáticas de narcocultura en los modelos del progreso económico y prestigio social. Desafíos, 1 (26), 199-234. 


\section{Anexo: Encuesta aplicada}

No de encuesta:

Universidad:

Carrera / Facultad:

Semestre cursado: Edad:

Género:

Estrato socioeconómico:

Lugar de origen o nacimiento (Ciudad / Municipio):

¿De alguna manera usted se considera víctima o ha recibido impactos directos o indirectos del conflicto armado?

\section{A. CONOCIMIENTO GENERAL SOBRE EL PROCESO DE PAZ EN COLOMBIA}

A-1. ¿Qué tanto considera usted que conoce acerca de la agenda y los avances de negociación en la mesa de La Habana?

\begin{tabular}{|l|l|}
\hline A. Ni siquiera he oído hablar de un proceso de paz & \\
\hline B. Sólo he oído mencionar, realmente no conozco mucho del proceso & \\
\hline C. Conozco algo de la mesa de negociación y el proceso de paz & \\
\hline D. Conozco mucho acerca de la mesa de negociación y el proceso de paz & \\
\hline
\end{tabular}

\section{B. REFRENDACIÓN}

B-1. ¿Está usted de acuerdo con que el gobierno Santos consulte a la sociedad colombiana el contenido de un acuerdo con la guerrilla de las FARC?

\begin{tabular}{|l|l|l|l|}
\hline Sí & & No & \\
\hline
\end{tabular}

B-2. En caso de ser afirmativa la respuesta anterior, usted considera importante consultar a la sociedad colombiana el contenido de los acuerdos con la guerrilla de las FARC porque:

\begin{tabular}{|l|l|}
\hline A. Sectores opositores necesitan manifestar su inconformidad frente al proceso & \\
\hline B. El gobierno Santos necesita buscar el apoyo social al proceso & \\
\hline C. Otro. ¿Cuál? & \\
\hline
\end{tabular}

B-3. ¿Cuál sería el mecanismo idóneo para consultar el contenido de los acuerdos a la sociedad colombiana?

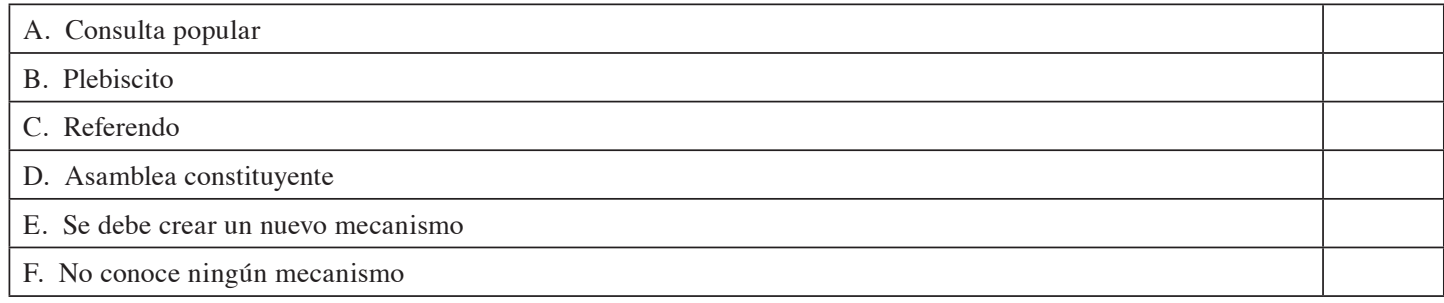


B-4. En el caso en que la sociedad colombiana manifestara no refrendar el acuerdo, usted considera que:

\begin{tabular}{|l|l|}
\hline A. Se debe intentar salvar el proceso de paz & \\
\hline B. Se deben romper las conversaciones & \\
\hline C. Esperar que el siguiente gobierno decida & \\
\hline
\end{tabular}

B-5. En caso en que se consulte a la sociedad colombiana el contenido de los acuerdos con la guerrilla de las FARC, usted apoyaría los mismos si se cumpliera con una de estas condiciones:

\begin{tabular}{|l|l|}
\hline A. Las FARC pidieran perdón y pagarán cárcel & \\
\hline B. Hubiera un cese bilateral al fuego & \\
\hline C. El gobierno garantizara participación política de las FARC & \\
\hline D. Otra, ¿̨cuál? & \\
\hline
\end{tabular}

\section{RECONCILIACIÓN}

C-1. Usted, como joven universitario, ¿cree posible el perdón y la reconciliación entre el conjunto de la sociedad colombiana y los miembros desmovilizados de las FARC?

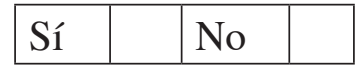

C-2. Con cuál de las siguientes afirmaciones estaría usted más de acuerdo

\begin{tabular}{|l|l|}
\hline A. La mayoría de los miembros desmovilizados de las FARC deberían pagar cárcel por mucho tiempo & \\
\hline B. La mayoría de los miembros desmovilizados de las FARC deberían pagar cárcel por algún tiempo & \\
\hline C. La mayoría de los miembros desmovilizados de las FARC no deberían pagar cárcel & \\
\hline D. Algunos miembros de las FARC deberían pagar cárcel por mucho tiempo & \\
\hline E. Algunos miembros de las FARC deberían pagar cárcel por algún tiempo & \\
\hline F. Ningún miembro de las FARC deberían pagar cárcel & \\
\hline
\end{tabular}

C-3. Si no fuera a través de la cárcel, ¿con cuál de los siguientes mecanismos estaría usted mucho más de acuerdo con que un desmovilizado de las FARC se resarciera ante la sociedad colombiana?

\begin{tabular}{|l|l|}
\hline A. Trabajo social y comunitario & \\
\hline B. Solicitud de perdón público ante la sociedad colombiana & \\
\hline C. Que contribuya en el esclarecimiento de la verdad & \\
\hline D. Reparación a las víctimas & \\
\hline
\end{tabular}

C-4. En el eventual caso en que los desmovilizados de las FARC participen en política, usted considera que es mejor

\begin{tabular}{|l|l|}
\hline A. Que formen un nuevo partido político & \\
\hline B. Que hagan alianza con un partido político existente & \\
\hline C. Que inviten a formar una coalición multipartidista & \\
\hline
\end{tabular}


C-5. Cuál de las siguientes emociones reflejaría mejor lo que usted posiblemente sentiría frente a una persona que conoce y se entera que es desmovilizado de las FARC:

\begin{tabular}{|l|l|}
\hline A. Orgullo & \\
\hline B. Esperanza & \\
\hline C. Miedo & \\
\hline D. Odio & \\
\hline E. Indiferencia & \\
\hline F. Decepción & \\
\hline G. Otra. ¿Cuál? & \\
\hline
\end{tabular}

\section{D- CONFLICTO URBANO}

D-1.Usted considera que existe una relación entre las dinámicas del conflicto armado en Colombia y el conflicto urbano en Bogotá

\begin{tabular}{|l|l|l|l|}
\hline Sí & & No & \\
\hline
\end{tabular}

D-2. De 1 a 9, siendo 1 (mayor importancia) y 9 (menor importancia), establezca cuáles de las siguientes son las manifestaciones más recurrentes de los conflictos urbanos:

\begin{tabular}{|l|l|}
\hline A. Pobreza & \\
\hline B. Desempleo & \\
\hline C. Acceso a la educación & \\
\hline D. Movilidad & \\
\hline E. Ausencia de espacios públicos & \\
\hline F. Cultura ciudadana & \\
\hline G. Violencia intrafamiliar & \\
\hline H. Inseguridad & \\
\hline I. Participación ciudadana & \\
\hline
\end{tabular}

D-3. De acuerdo a la respuesta anterior, ¿cuáles de estas manifestaciones son por causa y/o consecuencia del conflicto armado en Colombia?

D-4. En caso de firmarse un acuerdo de paz entre el gobierno Santos y la guerrilla de las FARC, ¿cuál cree usted es el nivel de incidencia en la transformación de los conflictos urbanos?:

\begin{tabular}{|l|l|}
\hline A. Nada incide & \\
\hline B. Poco incide & \\
\hline C. Alta incidencia & \\
\hline D. No sabe & \\
\hline
\end{tabular}


D-5. ¿Cuál es el nivel de incidencia del conflicto urbano en la prolongación y degradación del conflicto armado en Colombia:

\begin{tabular}{|l|l|}
\hline A. Nada incide & \\
\hline B. Poco incide & \\
\hline C. Alta incidencia & \\
\hline D. No sabe & \\
\hline
\end{tabular}

\section{E. ACTORES SOCIALES}

\section{E-1. Estable de las FARC:}

\begin{tabular}{|l|l|}
\hline A. Academia & \\
\hline B. Medios de comunicación & \\
\hline C. Empresarios & \\
\hline D. Iglesia & \\
\hline E. Organizaciones Sociales & \\
\hline F. Rama Judicial & \\
\hline G. Congreso de la República & \\
\hline H. Fuerzas Armadas & \\
\hline I. Víctimas & \\
\hline
\end{tabular}

E-2. Establezca de 1 a 10, siendo 1 (mayor incidencia) y 10 (menor incidencia), el nivel de incidencia de los siguientes personajes en caso de darse un acuerdo de paz entre el gobierno Santos y la guerrilla de las FARC:

\begin{tabular}{|l|l|l|}
\hline A. & Juan Manuel Santos & \\
\hline B. & Gustavo Francisco Petro Urrego & \\
\hline C. $\quad$ Martha Lucía Ramírez & & \\
\hline D. & Antanas Mockus Šivickas & \\
\hline E. Álvaro Uribe Vélez & \\
\hline F. $\quad$ Piedad Córdoba & \\
\hline G. Antonio Navarro Wolff & \\
\hline H. $\quad$ Alejandro Ordoñez & \\
\hline I. $\quad$ Fidel Castro & \\
\hline J. $\quad$ Barack Obama & \\
\hline
\end{tabular}

E-3. ¿Cuál es la importancia que generaría para su vida cotidiana un acuerdo de paz entre el Estado colombiano y la guerrilla de las FARC?

\begin{tabular}{|ll|l|}
\hline A. Nada importante & & \\
\hline B. Poco importante & & \\
\hline C. Importante & & \\
\hline D. Muy importante & \\
\hline
\end{tabular}


E-4. ¿Cuál es el aporte diferenciador de los jóvenes universitarios en la construcción de paz en Colombia? 
